\title{
Development of stripper harvester for paddy
}

\author{
Girishkumar Balasaheb Bhanage, P. U. Shahare, V. V. Aware, K. G. Dhandeand P. S. \\ Deshmukh
}

Department of Farm Machinery and Power,College of Agricultural Engineering and Technology, Dr. Balasaheb Sawant Konkan KrishiVidyapeeth, Dapoli, Ratnagiri (Maharahstra), INDIA

*Corresponding author E-mail: girish_agril@yahoo.co.in

Received: December 10, 2016; Revised received: May 5, 2017; Accepted: September 10, 2017

Abstract: Konkan is the coastal part of Maharashtra between Western Ghat and Arabian seacoast. Rice is a major crop grown over 3.86 lakh hectares. Stripper harvesting technology, which strips only seeds and keeps straw erected in the field present bright prospect for the development of small, light, efficient mechanism by reducing number of operation with increased capacity and lesser power compared to conventional cutter bar combine harvester. The big machines like combine harvester and high capacity threshers for harvesting and threshing have limitations. A prototype of paddy stripper harvester was developed considering the limitation of Konkan like small, fragmented land, hilly, terrace farming and high rainfall. It consisted of stripping mechanism, grain tank, hydraulic system, steering system, gear box, engine, cage wheel and chassis. The arrangement of V-belt and set of pulleys were made to transmit power from gear box to stripper rotor. The effect of forward speed and peripheral speed on shattered and un-stripped grain loss was studied. The shattered grain loss was decreased with increase in forward speed whereas decreased initially and then increased with increase in peripheral speed. The un-stripped grain loss was decreased with increase in forward and peripheral speed. The performance of the developed prototype was found better at forward speed of $2.25 \mathrm{~km} / \mathrm{h}$ and peripheral speed of $19.78 \mathrm{~m} / \mathrm{s}$. During final testing of prototype, shattered and unstripped grain loss was found 5.95 and $1.89 \%$, respectively. The average field capacity and field efficiency of paddy stripper harvester machine was found $0.14 \mathrm{ha} / \mathrm{h}$ and 69.38 per cent respectively.

Keywords: Grain loss, Harvester, Stripper, Stripping element

\section{INTRODUCTION}

Rice (Oriza sativa L.) is an important crop on which food security of the world is strongly associated as it is the staple food for half of the world's population (Aslam et al. 2015). India ranks second in the world with rice production of 106.54 million tonnes of paddy (Anonymous, 2015a). Konkan is the coastal part of Maharashtra, where rice is cultivated over an area of 3.86 lakh ha with an annual production of about 10.84 lakh tones with average $2810 \mathrm{~kg} / \mathrm{ha}$ productivity (Anonymous, 2015b). Farm mechanization saves time and labour, cuts down crop production cost in the long run, reduces post harvest losses, boosts crop output and farm income (Mehta et al. 2014). In Konkan region, rice cultivation requires immense labour force for transplanting, interculture, harvesting, collection and transportation, threshing and winnowing operation as 400, 200, 200, 224, 200 and 120 man hours per ha, respectively (Anonymous, 2012).

Stripping is a very popular harvesting concept that continues to challenge designers through the centuries (Tadoet al. 1998). The main advantages of stripper harvester are increase in harvesting capacity at a reduced power requirement and increased in combining hours availability at harvest. Most of the straw is left un-harvested in the field which can be harvested using reaper or sickle for animal feed or industrial composite. The reduced straw intake also offers potential for a reduction in size and weight for a machine of given capacity (Tadoet al. 1998). Stripping harvesting offers considerably increased work rate primarily due to the reduction in material other than grain (MOG) harvested and consequent increase in grain separation efficiency (Peiris, 1990). The commercial stripper by Shelbourne Reynolds, England, increases combine capacity by 50 to 100 per cent at a lower power requirement through the reduced amount of straw passing through the threshing and separating systems of the combine.International Rice Research Institute and Silsoe Research Institute UK, has developed stripper gatherer for paddy harvesting having capacity of 1 ha/ day (Douthwaiteet al. 1993)

In Konkan region paddy fields are very small $(0.02$ to 0.2 ha) with bigger bunds. Hence, for harvesting and threshing big machines like combine harvesters (4 and $2.5 \mathrm{~m}$ width) and high capacity threshers have limitation in Konkan region. Konkan is major tribal area of Sahyadri and west coast having small and fragmented land. Studies have shown that the male migration to urban areas and diversion of work force to non-farm 
sectors has brought women to center stage of all household activities in which rice farming is the most important one (Anonymous 2013a). The labours are scarce nowadays and their shortage, non availability at proper harvesting time and high wages resulting in rice cultivation as uneconomical enterprise. Due to changing climatic condition, rains are occurred and make the paddy fields more moist and sometimes water logged. Small and fragmented land of Konkan is major hurdle in Konkan agricultural mechanization.

Stripper harvesting technology can reduce the time required for threshing and winnowing operation with the light mechanism and lesser power compared to conventional cutter bar combine harvester. Its high capacity compared to conventional method can save the crop from rain damage in changing agro-climatic situation. The new indigenous small design of stripper harvester with cage wheel arrangement can work in wet condition stripping valuable product and harvesting the straw after recession of the moisture of filed for animal feed. If the stripping technology is indigenized, it can be better solution for present problem of agricultural mechanization for harvesting and threshing in Konkan region. Hence the aim of study is development and testing of stripper harvester for paddy.

\section{MATERIALS AND METHODS}

The harvester was developed to accomplish stripping of paddy panicles and collecting the stripped paddy material without harvesting the straw. The stripped paddy material partially threshing and winnowing was required. The biometric properties viz. plant height, panicle dropping height, panicle length in $\mathrm{mm}$ and number of tillers were measured. The stripper rotor height range was selected on the basis of plant height and panicle dropping height. The abrasion resistant and flexible industrial rubber material was used for stripping element (Peries, 1990 and Tado 2002). Slender arrow head stripping element was used having $900 \mathrm{~mm}$ length (Fig. 1).

Paddy stripper harvester was developed (Fig. 2)and the schematic views is shown in Fig.3. The components viz. stripper rotor, stripping element, hood and grain tank was developed and mounted on the available chassis of mini combine harvester (Make: SquzaSifang, China). The engine, gear box, steering and hydraulic systems components viz. hydraulic cylinder, hand pump and hose pipe available with the harvester was used for development of harvester. The cylindrical shape rotor (Fig. 4) of diameter $290 \mathrm{~mm}$ having length of $900 \mathrm{~mm}$ was made of Mild Steel sheet. Eight Mild Steel flat $(900 \times 40 \times 3 \mathrm{~mm})$ were welded on rotor for fixing the stripping element. The hood was provided on the stripper rotor to convey the stripped paddy material to the grain tank. It was made of MS sheet 18 SWG having size of $1000 \times 950 \mathrm{~mm}$. The front end of hood was made in dome shape for easy feeding of the crop to the stripper rotor. The clearance between the tip of stripper rotor and underside of the hood was kept $90 \mathrm{~mm}$ (Yuan and Lan 2007). Grain tank was developed for collecting the stripped paddy material. Hydraulic system was developed for adjusting height of stripper rotor. The diesel engine of $6.9 \mathrm{hp}(5.15 \mathrm{~kW})$ at 2400 rated speed was used as power source. The gear box is used for transmitting power to the drive wheel and stripper rotor. The power was transmitted from gear box to stripper rotor through $\mathrm{V}$-belt and set of pulleys. The gear box having three forward and one reverse gear was used for getting the desired motion to the stripper harvester. The cage wheels where developed for working under wet conditions.

The developed paddy stripper harvester was evaluated for its performance in field. The operational variables, forward speed and peripheral speed of stripper rotor were taken as independent variables. Shattered and unstripped grain loss efficiency was taken as performance parameters. The prototype was tested in field by varying forward speed $(1.65,1.98$ and $2.25 \mathrm{~km} / \mathrm{h})$ and peripheral speed of stripper rotor $(14.13,16.95,19.78$ and $22.6 \mathrm{~m} / \mathrm{s}$ ) using factorial randomized block design with three replication of each experiment. The parameters were computed as

Shattered grain loss $(\%)=\begin{array}{ll}\frac{\mathrm{W}_{\mathrm{s}}}{W_{p}} \times 100 \\ \begin{array}{ll}\frac{\mathrm{W}_{\mathrm{u}}}{W_{p}} \times 100 & \\ \text { Un-stripped grain loss }(\%)=1\end{array}\end{array}$

Where,

$\mathrm{W}_{\mathrm{s}}=$ Weight of shattered grain from unit area, $\mathrm{g}$

$\mathrm{W}_{\mathrm{p}}=$ Weight of production from unit area, $\mathrm{g}$

$\mathrm{W}_{\mathrm{u}}=$ Weight of un-stripped grain from unit area, $\mathrm{g}$

Based on the field performance evaluation of the paddy stripper harvester, best operating parameters were selected for final testing. Final testing was done for checking the feasibility for continuous and long duration harvesting of paddy.

\section{RESULTS AND DISCUSSION}

Effect of forward speed on shattered and unstripped grain loss: Analysis of variance (Table. 1) revealed that forward speed had a significant effect on shattered and un-stripped grain loss at 5 per cent level of significance. Fig. 5 and Fig. 6shows that relationship between forward speeds with shattered and unstripped grain loss, respectively. The slope of the curve shows that the shattered and un-stripped grain loss was decreased linearly with increase in forward speed from 1.65 to $2.25 \mathrm{~km} / \mathrm{h}$ within the tested range of the peripheral speed.Tado (2002) reported that shattered grain loss was decreased from 3 to $1.3 \%$ with increase in forward speed from 2 to $4 \mathrm{~km} / \mathrm{h}$. AlsoChegini (2012) observed that un-stripped grain loss was decreased 
Girishkumar Balasaheb Bhanage et al. / J. Appl. \& Nat. Sci. 9 (4): 1943 -1948 (2017)

Table 1. Analysis of variance for effect of forward speed and peripheral speed on shattered and un-stripped grain loss.

\begin{tabular}{|c|c|c|c|c|c|}
\hline \multirow[t]{2}{*}{ Source } & \multirow{2}{*}{$\begin{array}{l}\text { Degree of } \\
\text { freedom }\end{array}$} & \multicolumn{2}{|c|}{ Shattered grain loss } & \multicolumn{2}{|c|}{ Un-stripped grain loss } \\
\hline & & Mean square & F value & Mean square & F value \\
\hline Replication & 2 & 0.54 & 2.93 & 0.04 & 2.58 \\
\hline Forward speed (A) & 2 & 2.35 & $12.77^{*}$ & 1.45 & $76.51^{*}$ \\
\hline Peripheral speed (B) & 3 & 2.98 & $16.18^{*}$ & 1.24 & $65.54 *$ \\
\hline $\mathrm{A} \times \mathrm{B}$ & 6 & 0.02 & 0.16 & 0.02 & 1.55 \\
\hline Error & 22 & 0.18 & & 0.01 & \\
\hline Corrected Total & 35 & & & & \\
\hline
\end{tabular}

(* significance at $5 \%)$

Table 2. Combine effect of forward speed and peripheral speed on shattered grain loss.

\begin{tabular}{|c|c|c|c|c|}
\hline \multirow[b]{2}{*}{ Forward Speed, km/h } & \multicolumn{4}{|c|}{ Shattered grain loss, \% } \\
\hline & \multicolumn{4}{|c|}{ Peripheral speed, $\mathbf{m} / \mathbf{s}$} \\
\hline & 14.13 & 16.95 & 19.78 & 22.6 \\
\hline 1.65 & 7.75 & 7.12 & 6.47 & 6.90 \\
\hline 1.98 & 7.34 & 6.73 & 5.85 & 6.24 \\
\hline 2.25 & 6.86 & 6.34 & 5.61 & 5.90 \\
\hline
\end{tabular}

$\mathrm{SE} \pm 0.2481 ; \mathrm{CD}$ (at $5 \%) 0.1470$

Table 3. Mean value of combined effect of forward speed and peripheral speed on un-stripped grain loss.

\begin{tabular}{lllll}
\hline & \multicolumn{3}{l}{ Un-stripped grain loss, \% } & \\
\cline { 2 - 5 } Forward Speed, $\mathbf{~ k m} / \mathbf{h}$ & 14.13 & 16.95 & 19.78 & 22.6 \\
& 2.78 & 2.44 & 2.16 & 2.02 \\
1.65 & 2.51 & 2.16 & 1.70 & 1.55 \\
1.98 & 2.17 & 1.78 & 1.51 & 1.31 \\
2.25 & \multicolumn{4}{l}{} \\
\hline
\end{tabular}

$\mathrm{SE} \pm 0.0795 ; \mathrm{CD}$ (at $5 \%$ ) 0.0151

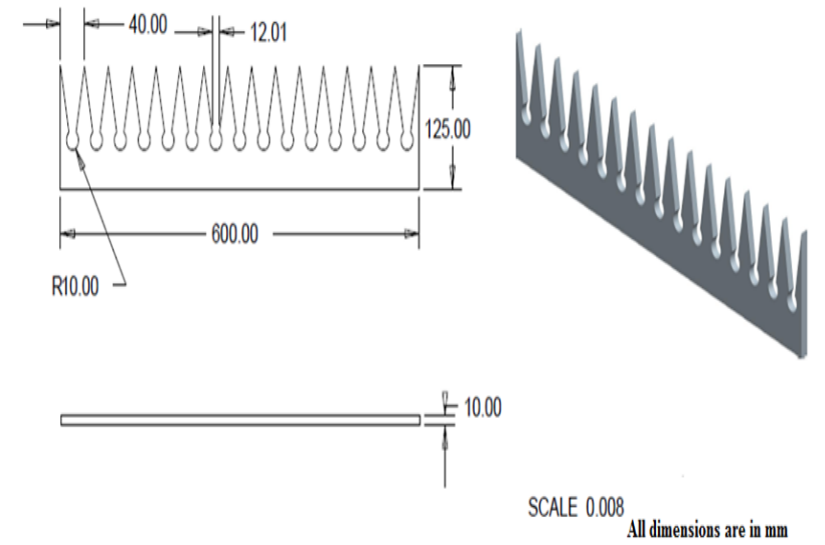

Fig. 1. Slender arrow head stripping element.

from 1.92 to $0.62 \%$ at 1.50 to $4.70 \mathrm{~km} / \mathrm{h}$ forward speed of stripper combine harvester for wheat. The minimum shattered and un-stripped grain loss was found $6.17 \%$ and $1.70 \%$ at $2.25 \mathrm{~km} / \mathrm{h}$ forward speed. Contact time of individual stripping element with straw was increased with increase in forward speed which might be possible reason for decreasingshattered andun-stripped grain loss.

Effect of peripheral speed rotor on shattered and un-stripped grain loss: Analysis of variance (Table. 1) revealed that peripheral speed of stripper rotor had a significant effect on shattered grain loss at 5 per cent level of significance. Fig. 7 shows that $2^{\text {nd }}$ order poly- nomial relationship between peripheral speed of stripper rotor and shattered grain loss. The curve shows that the shattered grain loss decreased initially and then increased with increase in peripheral speed within the tested range of the forward speed. The minimum shattered grain loss was found $5.99 \%$ at $19.78 \mathrm{~m} / \mathrm{s}$ peripheral speed. The shattered grain loss was decreased from 7.31 to $5.99 \%$ when increased the peripheral speed of stripper rotor from 14.13 to $19.78 \mathrm{~m} / \mathrm{s}$ and then increased. Tado (2002) observed that shattered grain loss was decreased from 2.4 to $1.7 \%$ with increase in peripheral speed of rotor from 650 to 850 $\mathrm{rpm}$ and increased again to $2.1 \%$ when the rotor speed was further increased to $950 \mathrm{rpm}$. The number of impacts of stripping element on the straw and also air velocity was increased with increase in peripheral speed. The increased number of impacts of stripping element on straw and air velocity decreases shattered grain loss initially and more grains at higher peripheral speed might have blocked by the crop wall at exists than entrance, reducing air velocity at outlet might have increased shattered grain loss onwards.

Analysis of variance (Table 1) revealed that peripheral speed had a significant effect on un-stripped grain loss at 5 per cent level of significance. Fig. 8 shows that the un-stripped grain loss was decreased linearly with increase in peripheral speed within the tested range of the forward speed. The minimum un-stripped grain loss was found $1.69 \%$ at $22.6 \mathrm{~m} / \mathrm{s}$ peripheral speed. 
Girishkumar Balasaheb Bhanage et al. / J. Appl. \& Nat. Sci. 9 (4): 1943 -1948 (2017)

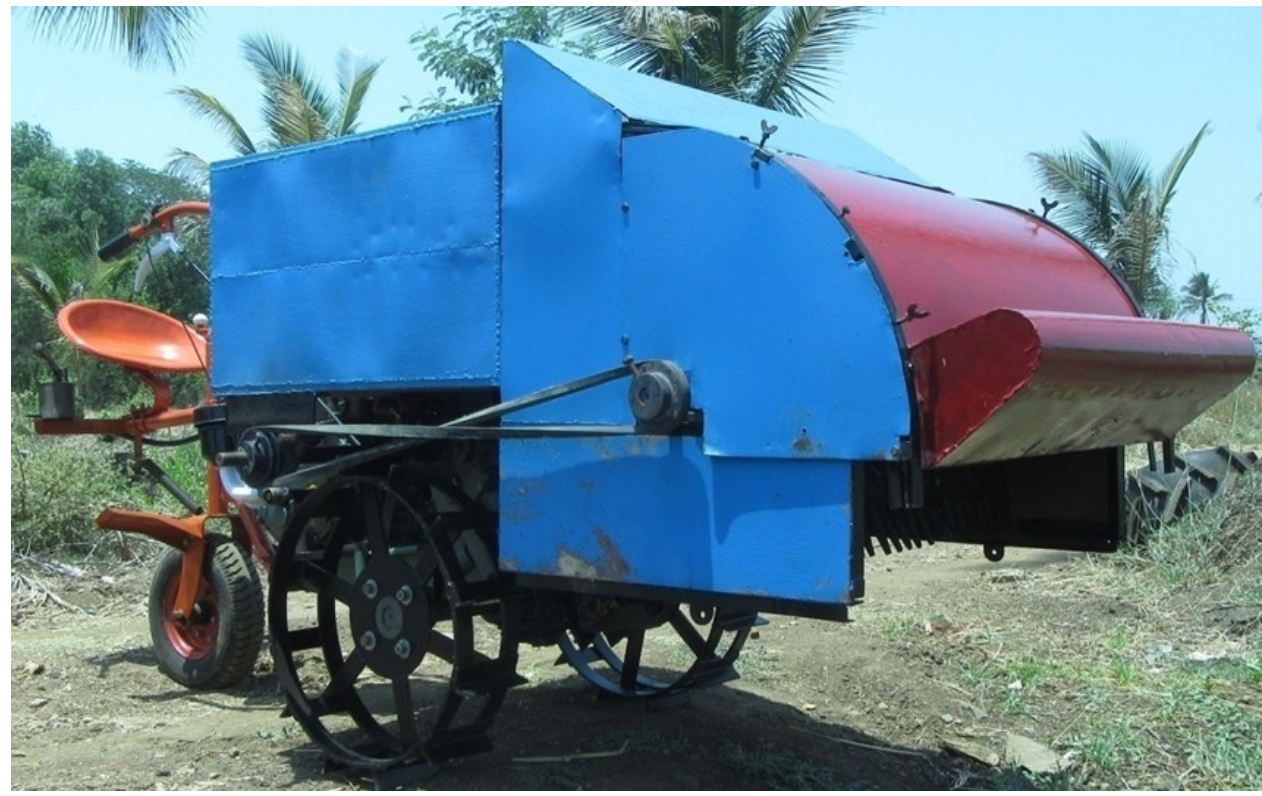

Fig. 2. Developed paddy stripper harvester.
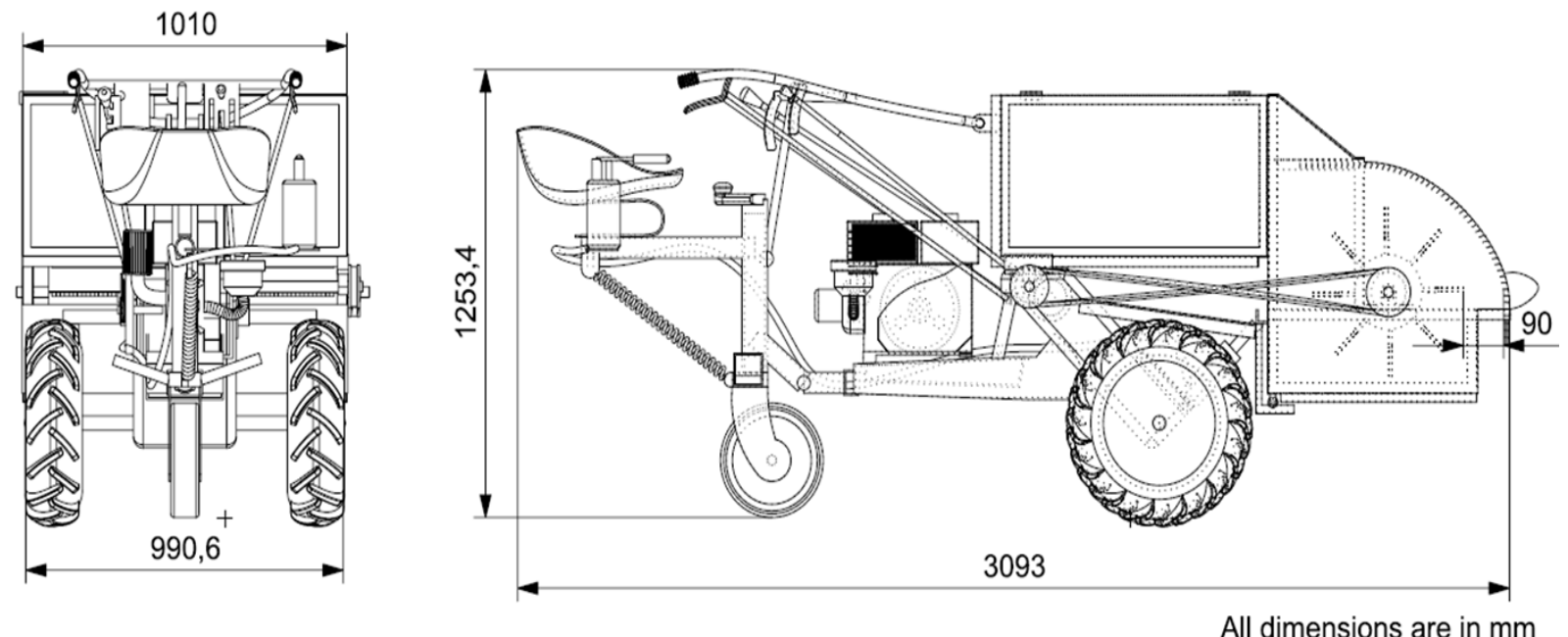

Fig. 3. Schematic views of Paddy Stripper Harvester.
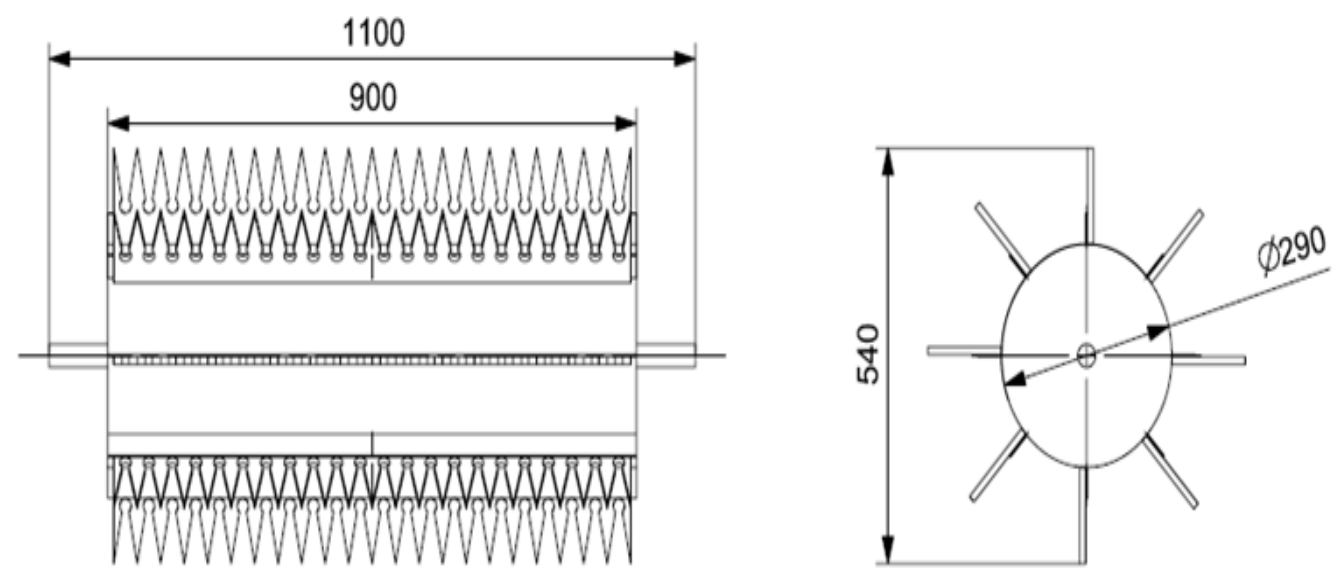

Fig. 4. Schematic views of stripper rotor. 


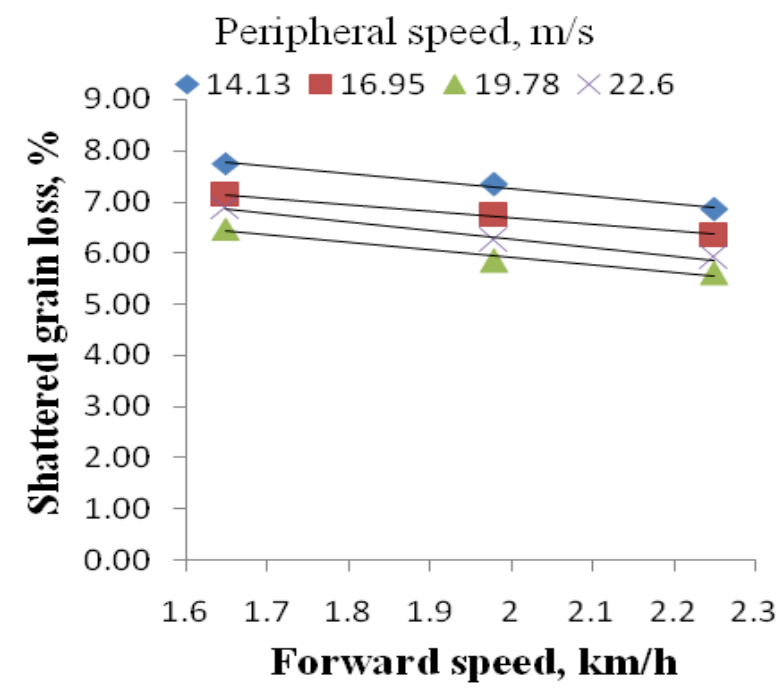

Fig. 5. Variation of shattered grain loss at different forward speed.

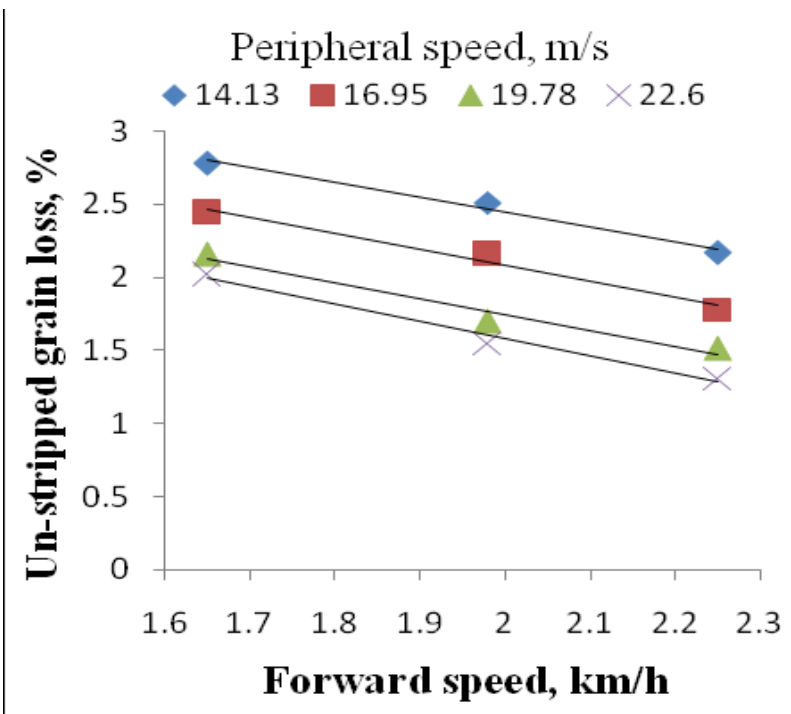

Fig. 6. Variation of un-stripped grain loss at different forward speeds.

The number of impacts of stripping element with straw was increased with increase in peripheral speed which might be responsible for reduced un-stripped grain loss by removing more grains from panicle. The similar type of trend was observed by Chegini (2012) for stripper combine harvester.

Combine effect of forward speed and peripheral speed on shattered grain loss: Analysis of variance revealed that the combine effect of forward speed and peripheral speed has statistically non-significant effect on shattered grain loss (Table. 1). The mean shattered grain loss for forward speed and peripheral speed is given in Table 2. The minimum shattered grain loss was found $5.61 \%$ at $19.78 \mathrm{~m} / \mathrm{s}$ peripheral speed and $2.25 \mathrm{~km} / \mathrm{h}$ forward speed. The maximum shattered grain loss was found $7.75 \%$ at $14.13 \mathrm{~m} / \mathrm{s}$ peripheral

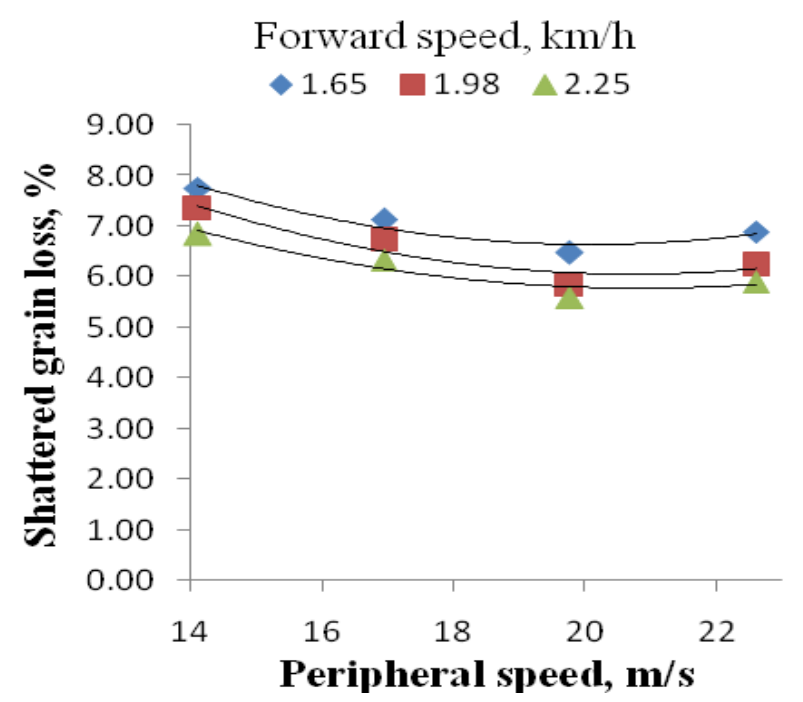

Fig. 7. Effect of peripheral speed of stripper rotor on shattered grain loss at different forward speed.

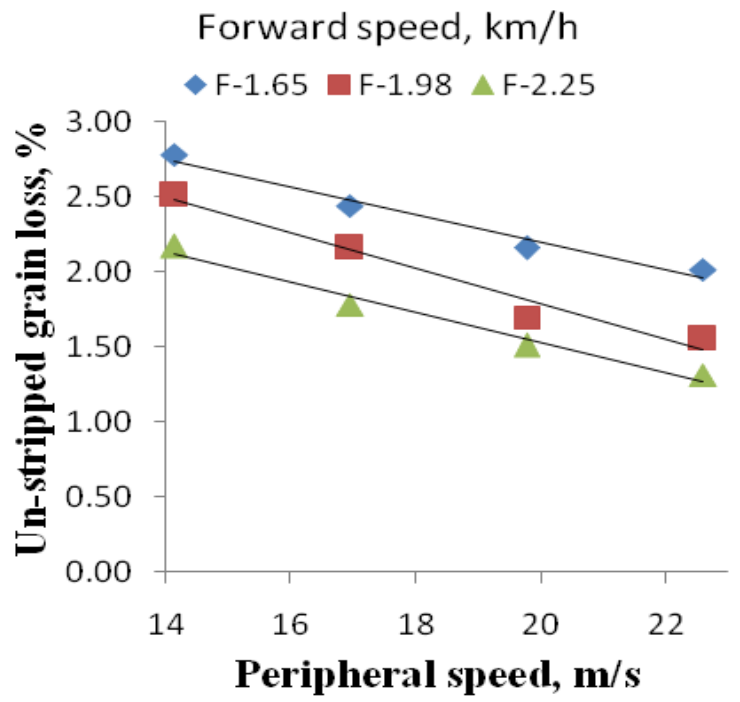

Fig. 8. Behavior of un-stripped grain loss at different peripheral speeds.

speed and $1.65 \mathrm{~km} / \mathrm{h}$ forward speed. The shattered grain loss found to be decreased with increased forward speed for all peripheral speeds ranging from 14.13 to $22.6 \mathrm{~m} / \mathrm{s}$. However, for all the forward speeds, the shattered grain loss was decreased up to peripheral speed $19.78 \mathrm{~m} / \mathrm{s}$ and later onincreased. The similar result was reported by Tado (2002) for stripper gatherer. The combine effect of the number of impact of stripping element on straw and contact time of stripping element with straw was increased which might be responsible for reduced shattered grain loss.

Combine effect of forward speed and peripheral speed on un-stripped grain loss: Analysis of variance revealed that the combine effect of forward speed and peripheral speed had non-significant effect on unstripped grain loss (Table, 1). The mean un-stripped 
grain loss for forward speed and peripheral speed is shown in Table 3. The minimum un-stripped grain loss was observed $1.40 \%$ at $22.6 \mathrm{~m} / \mathrm{s}$ peripheral speed and $2.25 \mathrm{~km} / \mathrm{h}$ forward speed. The maximum un-stripped grain loss was found $2.78 \%$ at $14.13 \mathrm{~m} / \mathrm{s}$ peripheral speed and $1.65 \mathrm{~km} / \mathrm{h}$ forward speed. The un-stripped grain loss found to be decreased with increase in forward speed and peripheral speed. The increased contact time and number of impact of stripping element on straw may be the possible reasons for reducing unstripped grain loss.

General observation: The shattered grain loss, and un -stripped grain loss was decreased with increase in forward speed. The un-stripped grain loss was decreased while shattered grain loss was decreased initially and then increased with increase in peripheral speed. The increase in forward speed of machine has resulted into better results with minimum shatteredand un-stripped grain loss. For increased peripheral speed the shattered grain loss decreased initially up to 19.78 $\mathrm{m} / \mathrm{s}$ peripheral speed and then increased whilethe decreased un-stripped grain loss. This indicated that, for minimum losses the developed stripper harvester should be run at higher forward speed.For minimum shattered grain loss and considering trend of viz. initially decreasing and then increasing indicated to run machine at $19.78 \mathrm{~m} / \mathrm{s}$ instead of higher $22.6 \mathrm{~m} / \mathrm{s}$ peripheral speed of stripper rotor.

Performance of stripper harvester: The stripper harvester was field tested for checking its suitability for continuous operation. The crop parameters viz. plant height, panicle dropping height, moisture content of grain and crop production per unit area were measured before final field test. These parameters were observed $66 \mathrm{~cm}, 55.5 \mathrm{~cm}, 20-22 \%$ and $255 \mathrm{~g}$. respectively. The stripping rotor height was kept $50 \mathrm{~cm}$ from the ground and hood height $10 \mathrm{~cm}$ below the plant height. The optimum values of the forward speed and peripheral speed of stripper rotor as $2.25 \mathrm{~km} / \mathrm{h}$ and $19.78 \mathrm{~m} / \mathrm{s}$ were taken. Plot of $24 \times 5 \mathrm{~m}$ were selected for testing. The average shattered grain loss and un-stripped grain loss were found $5.95 \%$ and $1.89 \%$, respectively. The average field capacity and field efficiency of paddy stripper harvesting machine was found to be $0.14 \mathrm{ha} / \mathrm{h}$ and 69.38 per cent respectively.

\section{Conclusion}

The forward speed and peripheral speed are the main factors affecting the performance of the stripper harvester. The shattered grain loss was found to be decreased with increase in forward speed while decreased initially and then increased with increase in peripheral speed.The un-stripped grain loss was found to be decreased with increase in peripheral speeds and forward speed. The stripper harvester was found to be suitable for harvesting of the paddy.

\section{REFERENCES}

Anonymous. (2012). Minutes of meeting on cost economics of paddy, Scheme on cost cultivation of crop, held at Department of Agricultural Economics, College of Agriculture, Dr. B.S.K.K.V. Dapoli, Dated $31^{\text {st }}$ march.

Anonymous (2015a). Rice market monitor, FAO, 18(1).

Anonymous (2015c). www.Mahaagri.gov.in, Crop Statistics Cropwise, Districtwise Area Production and Productivity.

Anonymous (2013b). Maharashtra water resource regulatory authority report, Water Resource Deparment Government of Maharashtra.

Aslam, M.M., M., Zeeshan, A. Irum, M.U. Hassan, S. Ali, R. Hussain, P.M.A. Ramzani, and M.F. Rashid. (2015). Influence of seedling age and nitrogen rates on productivity of Rice (Oryza sativa L.): A Review. American Journal of Plant Sciences, 6: 1361-1369.

Chegini, G.R. and S.V. Mirnezami. (2012). Analysis and comparison of wheat losses in two harvesting methods. Agric. Engg. Inter. CIGR Journal. 14(3): 91-98.

Doutwaite, B., Quick, G.R., and C.J.M. Tado. (1993). The stripper gatherer system for small-area rice harvesting. International Agriculture Engineering Journal, 2(4): 183-194.

Mehta, C.R., N.S. Chandel, T. Sentilkumar and K.K. Singh. (2014). Trends of agricultural mechanization in India. Policy brief, ESCAP CSAM. Issue 2.

Peiris, R.T.C. (1990). Development and evaluation of a rice stripping header system. Tropical Agril. Research. 2: 123-141.

Tado, C.J.M., P. Wacker, H.D. Kutzbach and D.C. Suministrado. (1998). Development of stripper harvesters: A Review. J. Agric. Engg. Res. 71: 103-112.

Tado, C. J. M. (2002). Influence on the performance of the stripper rotor in rice. Published $\mathrm{Ph}$. D Dissertation, Institute of Agricultural Engineering, University of Hohenheim, Germany.

Yuan J. and Y. Lan. (2007). Development of a cereal stripping harvester. Agril. Engg. Inter.: the CIGR E-journal. Manuscript PM 07 009. Vol. IX. September. 